\title{
Electromagnetic Field and $\Gamma$ Aminobutyric Acid a Receptors Interaction in the Fear Response
}

\author{
${ }^{1}$ Taherianfard, M., ${ }^{2}$ A. Bahaodini, ${ }^{3}$ M. Fazeli, ${ }^{2}$ S. Keshtkaran and ${ }^{2}$ S. Karimi Haghighi \\ ${ }^{1}$ Department of Physiology, Faculty of Veterinary Medicine, Shiraz University, Shiraz, Iran \\ ${ }^{2}$ Department of Biology, Faculty of Basic Science, Shiraz University, Shiraz, Iran \\ ${ }^{3}$ Department of Pharmacology, Faculty of Veterinary Medicine, Shiraz University, Shiraz, Iran
}

Received 2012-05-08, Revised 2013-05-26; Accepted 2013-07-13

\begin{abstract}
Freezing behavior is a fearful reaction to specific stimuli, most commonly observed by animals. One of the neurotransmission system most consistently linked with fear response is the GABAergic system, in which $\mathrm{GABA}$ through $\mathrm{GABA}_{\mathrm{A}}$ receptor can influence fear response. The aim of the present investigation was to examine the effect of IP injection of muscimol (GABA $A_{A}$ agonist) and bicuculline $\left(\mathrm{GABA}_{\mathrm{A}}\right.$ antagonist) with and without EMF exposure on the frequency of fear response. Fifty adult male rats weighing 180-200 g were used. Animals were divided in ten groups, of which five groups were exposed to ELF-EMF for 30 days at $8 \mathrm{~h} \mathrm{day}^{-1}$ in a solenoid, creating an electromagnetic field of $500 \mu \mathrm{T}$ by a $50 \mathrm{~Hz}$ electrical current created. Animals were then treated with various doses of muscimol and bicuculline before being exposed to electrical shock. Each animal were received 100 electrical shocks every session. After shock induction, the fear response was determined by monitoring the reaction of shocked animals to a normal rat which was placed in the electroshock chamber. Data were analyzed by Mann-Whitney test and $\mathrm{p}<0.05$ was considered as significant level. It was shown that injection of muscimol at $0.5 \mathrm{mg} \mathrm{kg}^{-1}$ in group with and without EMF exposure, significantly decreased the frequency of fear response but muscimol at $2 \mathrm{mg} \mathrm{kg}^{-1}$ only in group exposed to EMF significantly decreased frequency of fear response. Bicuculline significantly decreased frequency of fear response in group without EMF exposure, but it significantly increased the frequency of fear response in group with EMF exposure. Results indicated that interaction of $\mathrm{GABA}_{\mathrm{A}}$ receptors and EMF exposure possibly involved in the modulation of fear response.
\end{abstract}

Keywords: Fear Response, EMF, Muscimol, Bicuculline, Freezing Behavior, Significantly Decreased, Injection of Muscimol, Electroshock Chamber, Decreased Frequency, Electrical Shock

\section{INTRODUCTION}

Along with technological advances and extensive use of electrical devices, exposure to extremely low frequency $(50 \mathrm{~Hz})$ Electromagnetic Field (ELF-EMF) has extensively been increased and seems to have a significant effect on public and occupational health (Bracken et al., 1995; Forgacs et al., 2004). $50 \mathrm{~Hz}$ electromagnetic field is generated by power lines, transformers and electrical devices which can be found in our living environment. This has raised some concerns about the effects of ELF-EMF on human health (Forgacs et al., 2004).

It has been shown that there is disruption in the activity of serotonergic, dopaminergic and GABAergic system in social fear animal models (Li et al., 2001). Subcutaneous administration of phenibut $\left(\mathrm{GABA}_{\mathrm{A}}\right.$ agonist) led to reduction in the probability of passive defensive (freezing) reactions in rabbits (Zyablitseva and Pavlova, 2008). Intra dorsal periaquductal gray injection Corresponding Author: Taherianfard, M., Department of Physiology, Faculty of Veterinary Medicine, Shiraz University, Shiraz, Iran 
of muscimol produces an expected inhibitory effect on the anxiety-related responses and freezing whereas these injections into the inferior colliculus produce quite opposite (Reimer et al., 2008).

Bicuculline microinjection in the medial hypothalamus causes panic-like responses in laboratory animals and the elaborated escape behavior organized in both dorsomedial and ventromedial hypothalamic nuclei followed by significant innate-fear-induced antinociception (Freitas et al., 2009). Intracortical application of bicuculline attenuates the freezing behavior induced by contextual fear conditioning (Matsumoto et al., 2005). Pentylentertrazol (GABA antagonist) at dose of $30 \mathrm{mg} \mathrm{kg}^{-1}$ significantly decreases freezing reaction (Zienowicz et al., 2007).

Several studies indicate the effect of electromagnetic field on fear response. It has been shown that acquisition of conditioned fear was strongly inhibited in animals exposed to complex magnetic fields (Whissell et al., 2009). Prenatal exposure to physiologically-patterned magnetic fields within a specific "window" of intensities that overlap with values found in many human habitats may produce long-term changes in fear behaviors (St-Pierre and Persinger, 2008). One of the neurochemical system most consistently linked with fear is the GABAergic system. GABA levels significantly differ in fearconditioned compared to non-fear-conditioned animals, supporting the role of GABA in fear (Rea et al., 2009). But there are a few studies on the interaction of electromagnetic field and $\mathrm{GABA}_{\mathrm{A}}$ receptor modulation. The aim of the present study was to investigate the interaction of electromagnetic field (as environmental factor) and modulation of $\mathrm{GABA}_{\mathrm{A}}$ receptor by IP injection of muscimol $\left(\mathrm{GABA}_{\mathrm{A}}\right.$ agonist) and bicuculline ( $\mathrm{GABA}_{\mathrm{A}}$ antagonist) on the fear behavior.

\section{MATERIALS AND METHODS}

\subsection{Animals}

All the procedures involving animal subjects were reviewed and approved by the Institutional Research Ethics Committee of the School of Veterinary Medicine of Shiraz University.

Fifty adult male Sprague-Dawley rats (180-200 gr) were used. The rats were acclimatized for 1 week before being used for the experiment. After preincubation at the same conditions, animals were randomly divided into 10 groups $(n=5)$ : Sham 1 (received normal saline at the same volume of drugs); Sham 2 (exposed to EMF and received normal saline); Experimental 1 (received muscimol at $0.5 \mathrm{mg} \mathrm{kg}^{-1}$ ); Experimental 2 (received muscimol at $2 \mathrm{mg} \mathrm{kg}^{-1}$ ) Experimental 3 (exposed to EMF and received muscimol at $0.5 \mathrm{mg} \mathrm{kg} \mathrm{kg}^{-1}$ ); Experimental 4 (exposed to EMF and received muscimol at $2 \mathrm{mg} \mathrm{kg}^{-1}$ ) Experimental 5 (received bicuculline at 1 $\mathrm{mg} \mathrm{kg}^{-1}$ ); Experimental 6 (received bicuculline at $3 \mathrm{mg}$ $\mathrm{kg}^{-1}$ ); Experimental 7 (exposed to EMF and received bicuculline at $1 \mathrm{mg} \mathrm{kg}^{-1}$ ) and Experimental 8 (exposed to EMF and received bicuculline at $3 \mathrm{mg} \mathrm{kg}^{-1}$ ).

\subsection{Electromagnetic Field Exposure System}

Five groups of animals were exposed to ELF-EMF for 30 days at $8 \mathrm{~h} \mathrm{day}^{-1}$ in a solenoid. The solenoid created an electromagnetic field of $500 \mu \mathrm{T}$ by a $50 \mathrm{~Hz}$ electrical current. Humidity, temperature $\left(23-24^{\circ} \mathrm{C}\right)$ and photoperiod (12 h dark: $12 \mathrm{~h}$ light) reflected natural conditions and were similar in all groups.

\subsection{Drugs}

Muscimul and bicuculline (purchased from Sigma Aldrich Co) were diluted in isotonic saline $(0.9 \%)$ and injected Intraperitoneally (IP).

\subsection{Behavioral Testing}

Fear response was induced by application of 0.2 $\mathrm{mA}$ electrical current stimulation applied every $3 \mathrm{sec}$ for $5 \mathrm{~min}$, i.e., each animal was received 100 electrical shocks every session. After shock induction, the fear response was determined by monitoring the reaction of shocked animals to a normal rat which was placed in the electroshock chamber. The number of freezing behavior as the sign of fear response was appropriately recorded for $20 \mathrm{~min}$.

\subsection{Statistical Analysis}

Data were analyzed using SPSS (version 18). Non parametric test Mann-Whitney was carried out to assess the effects of muscimul and bicuculline on fear response. Data were presented as Mean \pm SEM. The significant value were considered $\mathrm{p}<0.05$.

\section{RESULTS}

IP injection of muscimol at $0.5 \mathrm{mg} \mathrm{kg}^{-1}$ significantly $(p<0.05)$ decreased the frequency of fear response in comparison to that of sham 1; but muscimol at $2 \mathrm{mg} \mathrm{kg}^{-1}$ did not (Table 1). IP injection of muscimol at both doses in animals exposed to EMF significantly $(p<0.05)$ decreased frequency of fear response in comparison to that sham 2 (Table 1). 
Taherianfard, M. et al. / Current Research in Psychology 4 (1): 1-5, 2013

Table 1. Interaction of EMF and muscimul on frequency of fear response

\begin{tabular}{|c|c|c|c|}
\hline Experiment type & Groups & & $\begin{array}{l}\text { Frequency of } \\
\text { fear response }\end{array}$ \\
\hline \multirow[t]{3}{*}{ Without exposure to EMF } & Sham 1 & & $7.6 \pm 0.93$ \\
\hline & Experimental 1 & Muscimul $0.5 \mathrm{mg} \mathrm{kg}^{-1}$ & $2.2 \pm 0.8$ \\
\hline & Experimental 2 & Muscimul $2 \mathrm{mg} \mathrm{kg}^{-1}$ & $6.6 \pm 2.68^{\mathrm{a}}$ \\
\hline \multirow[t]{3}{*}{ With exposure to EMF } & Sham 2 & & $5 \pm 0.12^{\mathrm{a}}$ \\
\hline & Experimental 3 & Muscimul $0.5 \mathrm{mg} \mathrm{kg}^{-1}$ & $2.75 \pm 1.11^{\mathrm{b}}$ \\
\hline & Experimental 4 & Muscimul $2 \mathrm{mg} \mathrm{kg}^{-1}$ & $2 \pm 1.15^{\mathrm{b}}$ \\
\hline
\end{tabular}

Dissimilar characters showed significant level at $\mathrm{p}<0.05$

Table 2. Interaction of EMF and Bicuculline on frequency of fear response

\begin{tabular}{llll}
\hline Experiment type & Groups & & $\begin{array}{l}\text { Frequency of } \\
\text { fear response }\end{array}$ \\
\hline Without exposure to EMF & Sham 1 & & $7.6 \pm 0.93^{\mathrm{a}}$ \\
& Experimental 5 & Bicuculline $1 \mathrm{mg} \mathrm{kg}^{-1}$ & $3.8 \pm 1.91^{\mathrm{b}}$ \\
& Experimental 6 & Bicuculline $3 \mathrm{mg} \mathrm{kg}^{-1}$ & $9.6 \pm 1.12^{\mathrm{a}}$ \\
With exposure to EMF & Sham 2 & Bicuculline $1 \mathrm{mg} \mathrm{kg}^{-1}$ & $5 \pm 0.12^{\mathrm{b}}$ \\
& Experimental 7 & Bicuculline 3 $\mathrm{mg} \mathrm{kg}^{-1}$ & $13 \pm 2.7^{\mathrm{c}}$ \\
& Experimental 8 & $14.2 \pm 3.58^{\mathrm{c}}$ \\
\hline
\end{tabular}

Dissimilar characters showed significant level at $\mathrm{p}<0.05$

IP injection of bicuculline at $1 \mathrm{mg} \mathrm{kg}^{-1}$ significantly $(p<0.05)$ decreased frequency of fear response in comparison to that of sham 1; but bicuculline $3 \mathrm{mg} \mathrm{kg}^{-1}$ did not (Table 2). IP injection of bicuculline at both doses in animals exposed to EMF significantly $(p<0.05)$ increased frequency of fear response in comparison to that of sham 2 (Table 2).

Sham 2 group exposed to EMF showed a significant $(p<0.05)$ decrease in the frequency of fear response in comparison to that of sham 1 (Table 1 and 2).

\section{DISCUSSION}

Some investigations show that EMF exposure can affect behaviors such as passivity, situational anxiety and fear response (Balassa et al., 2009; St-Pierre and Persinger, 2008; Whissell et al., 2009).

In the present study muscimul at $0.5 \mathrm{mg} \mathrm{kg}{ }^{-1}$ significantly decreased the frequency of fear response, but muscimul at $2 \mathrm{mg} \mathrm{kg}^{-1}$ had not effect. Muscimol infusion impaired differential fear responding as the level of freezing to inhibitory conditioned stimulus was indiscriminable from that to excitatory conditioned stimulus (Lee and Choi, 2012). Muscimol injections into the Anterior Hypothalamic Nucleus (AHN) and Ventromedial Nucleus of the Hypothalamus (VMHDM) significantly reduced conditioned freezing whereas inhibition of $\mathrm{GABA}_{\mathrm{A}}$ transmission increased this conditioned response in the AHN (Santos and Brandao, 2011). Furthermore the $\mathrm{GABA}_{\mathrm{A}}$ receptor agonists diazepam (3 and $6 \mathrm{mg} \mathrm{kg}^{-1}$ ) and chlordiazepoxide (10 $\mathrm{mg} \mathrm{kg}^{-1}$ ) significantly reduced the expression of fearpotentiated startle post-training (Risbrough et al., 2003).

In the present study bicuculline at $1 \mathrm{mg} \mathrm{kg}{ }^{-1}$ significantly decreased the frequency of fear response, but bicuculline $3 \mathrm{mg} \mathrm{kg}^{-1}$ had not effect. Microinjections of the $\mathrm{GABA}_{\mathrm{A}}$ receptor antagonist bicuculline into the dorsal periaqueductal grey matter have been used to evoke explosive defensive reactions and it has been proposed that it is more logical to study these responses as physiologic demonstration of fear (Coimbra et al., 2006). Local infusions of semicarbazide or bicuculline into inferior colliculus caused freezing and escape, respectively, in a dosedependent manner (Borelli et al., 2006).

IP administration of $2 \mathrm{mg} \mathrm{kg}^{-1}$ midazolam $\left(\mathrm{GABA}_{\mathrm{A}}\right.$ agonist) reduced conditioned freezing, whereas administration of $1 \mathrm{mg} \mathrm{kg}^{-1}$ bicuculline only marginally potentiated conditioned freezing (Zhang and Cranney, 2008). Donatti and Leite-Panissi (2009) showed that muscimol injection into basolateral nuclei of amygdala decreased tonic immobility duration as fear mark, whereas bicuculline injection to that region increased it.

In the present study EMF led to diminished frequency of fear response. McKay (2000) reported that magnetic fields display evidence of forgetting, as inferred by their 
marked attenuation of freezing behavior, during contextual extinction $24 \mathrm{~h}$ later. These results can be due to alters in the response of receptor, up regulation of receptor or neurotransmitter level alteration (Varani et al., 2002). In the present study muscimul at both doses significantly decreased the frequency of fear response in animals were exposed to EMF and bicuculline at both doses significantly increased the frequency of fear response in animals were exposed to EMF. In the literature there was not any study related to interaction of EMF and GABAergic system on fear response; so it seems that clarification of possible mechanisms behind the observed effect needs further studies. According to present data it seems that co-administration of muscimol potentiated EMF-induced decrease in the frequency of fear, while bicuculline had opposite effect.

\section{CONCLUSION}

Our results indicated that:

- In animals that there was not exposure to EMF both of the muscimul and bicuculline in low dose decreased the frequency of fear response

- In animal were exposed to EMF, muscimol at both doses significantly decreased the frequency of fear response and bicuculline at both doses significantly increased it

\section{REFERENCES}

Balassa, T., R. Szemerszky and G. Bardos, 2009. Effect of short-term $50 \mathrm{~Hz}$ electromagnetic field exposure on the behavior of rats. Acta Physiol. Hung., 96: 437-448. DOI: 10.1556/APhysiol.96.2009.4.4

Borelli, K.G., C. Ferreira-Netto and M.L. Brandao, 2006. Distribution of Fos immunoreactivity in the rat brain after freezing or escape elicited by inhibition of glutamic acid decarboxylase or antagonism of GABA-A receptors in the inferior colliculus. Behav. Brain Res., 170: 84-93. DOI: 10.1016/j.bbr.2006.02.015

Bracken, M.B., K. Belanger, K. Hellenbrand, L. Dlugosz and T.R. Holford et al., 1995. Exposure to electromagnetic fields during pregnancy with emphasis on electrically heated beds: Association with birth weight and intrauterine growth retardation. Epidemiology, 6: 263-270. DOI: $10.2307 / 3702390$
Coimbra, N.C., R.D. Oliveira, R.L. Freitas, S.J. Ribeiro and K.G. Borelli et al., 2006. Neuroanatomical approaches of the tectumreticular pathways and immunohistochemical evidence for serotonin-positive perikarya on neuronal substrates of the superior colliculus and periaqueductal gray matter involved in the elaboration of the defensive behavior and fearinduced analgesia. Exp. Neurol., 197: 93-112. DOI: 10.1016/j.expneurol.2005.08.022

Donatti, A.F. and C.R. Leite-Panissi, 2009. GABAergic antagonist blocks the reduction of tonic immobility behavior induced by activation of 5-HT2 receptors in the basolateral nucleus of the amygdala in guinea pigs. Brain Res. Bull., 79: 358-364. DOI: 10.1016/j.brainresbull.2009.04.016

Forgacs, Z., Z. Somosy, G. Kubinyi, H. Sinay and J. Bakos et al., 2004. Effects of whole-body $50-\mathrm{Hz}$ magnetic field exposure on mouse Leydig cells. Scient. World J., 4: 83-90. DOI: 10.1100/tsw.2004.182

Freitas, R.L., A. Uribe-Marino, M.A. CastiblancoUrbina, D.H. Elias-Filho and N.C. Coimbra, 2009. $\mathrm{GABA}_{\mathrm{A}}$ receptor blockade in dorsomedial and ventromedial nuclei of the hypothalamus evokes panic-like elaborated defensive behaviour followed by innate fear-induced antinociception. Brain Res., 1305: 118-131. DOI: 10.1016/j.brainres.2009.09.096

Lee, Y.K. and J.S. Choi, 2012. Inactivation of the medial prefrontal cortex interferes with the expression but not the acquisition of differential fear conditioning in rats. Exp. Neurobiol., 21: 23-29. DOI: 10.5607/en.2012.21.1.23

Li, D., P. Chokka and F. Tibbo, 2001. Toward an integrative understanding of social phobia. J. Psychiatr. Neurosci., 26: 190-202. PMID: 11394189

Matsumoto, M., H. Togashi, A. Kaku, M. Kanno and K. Tahara et al., 2005. Cortical GABAergic regulation of dopaminergic responses to psychological stress in the rat dorsolateral striatum. Synapse, 56L: 117-121. DOI: 10.1002/syn.20131

McKay, B.E., M.A. Persinger and S.A. Koren, 2000. Exposure to a theta-burst patterned magnetic field impairs memory acquisition and consolidation for contextual but not discrete conditioned fear in rats. Neurosci. Lett., 292: 99-102. PMID: 10998558 
Rea, K., Y. Lang and D.P. Finn, 2009. Alterations in extracellular levels of gamma-aminobutyric acid in the rat basolateral amygdala and periaqueductal gray during conditioned fear, persistent pain and fearconditioned analgesia. J. Pain, 10: 1088-1098. DOI: 10.1016/j.jpain.2009.04.019

Reimer, A.E., A.R. Oliveira and M.L. Brandao, 2008. Selective involvement of gabaergic mechanisms of the dorsal periaqueductal gray and inferior colliculus on the memory of the contextual fear as assessed by the fear potentiated startle test. Brain Res. Bull., 76: 545-550. DOI: 10.1016/j.brainresbull.2008.03.011

Risbrough, V.B., J.D. Brodkin and M.A. Geyer, 2003. GABA-A and 5-HT1A receptor agonists block expression of fear-potentiated startle in mice. Neuropsychopharmacology, 28: 654-663. DOI: 10.1038/sj.npp.1300079

Santos, J.M. and M.L. Brandao, 2011. Gabaergic mechanisms of anterior and ventromedial hypothalamic nuclei in the expression of freezing in response to a light conditioned stimulus. Psychol. Neurosci., $\quad 4$ : 211-217. DOI: 10.3922/j.psns.2011.2.006

St-Pierre, L.S. and M.A. Persinger, 2008. Behavioral changes in adult rats after prenatal exposures to complex, weak magnetic fields. Electromagn. Biol. Med., 27: 355-364. DOI: $10.1080 / 15368370802493396$
Varani, K., S. Gessi, S. Merighi, V. Iannotta and E. Cattabriga et al., 2002. Effect of low frequency electromagnetic fields on A2A adenosine receptors in human neutrophils. Br. J. Pharmacol., 136: 57-66. DOI: 10.1038/sj.bjp.0704695

Whissell, P.D., E.W. Tsang, B.P. Mulligan and M.A. Persinger, 2009. Prenatal exposures to LTPpatterned magnetic fields: Quantitative effects on specific limbic structures and acquisition of contextually conditioned fear. Int. J. Neurosci., 119: 1-14. DOI: $10.1080 / 00207450802480283$

Zhang, S. and J. Cranney, 2008. The role of GABA and anxiety in the reconsolidation of conditioned fear. Behav. Neurosci., 122: 1295-1305. DOI: 10.1037/a0013273

Zienowicz, M., A. Wislowska-Stanek, M. Lehner, E. Taracha and A. Skorzewska et al., 2007. Fluoxetine attenuates the effects of pentylenetetrazol on rat freezing behavior and c-Fos expression in the dorsomedial periaqueductal gray. Neurosci. Lett., 414: 252-256. DOI: 10.1016/j.neulet.2006.12.017

Zyablitseva, E.A. and I.V. Pavlova, 2008. Effects of the GABA receptor agonist phenibut on behavior and respiration in rabbits in emotionally negative situations. Neurosci. Behav. Physiol., 38: 555-562. DOI: $10.1007 / \mathrm{s} 1$ 1055-008-9025-2 